\title{
A holistic approach to establishing an effective learning environment for psychology
}

\author{
Lynne Cohen ${ }^{1}$, Paul Chang, Julie Ann Pooley and Lisbeth Pike \\ School of Psychology, Edith Cowan University, Australia
}

\begin{abstract}
The impetus for the Enhancing Quality and Learning (EQUAL) programme evolved out of concerns held by the staff in the School of Psychology at Edith Cowan University (ECU) regarding the difficulties encountered by first year psychology students and the subsequent low retention rate of these students in the psychology course. The EQUAL programme focused on easing the transition of high school students into university studies by enhancing the social support networks of commencing students. The programme was designed to be an holistic approach to enhancing a sense of belonging to the School of Psychology and comprised seven components. These are peer mentoring, the formation of learning communities, curriculum reforms, tutor training, orientation, the development of student portfolios and school liaison. EQUAL is now an integral part of the learning experience for all psychology students at ECU. Evaluations of the EQUAL programme indicate greater student satisfaction with the psychology course and increased retention rates.
\end{abstract}

This paper describes a programme that has had a positive impact on the learning experiences of first year students in the School of Psychology at Edith Cowan University (ECU) in Western Australia. The approach taken was holistic in the sense that the individual activities within the programme targeted specific areas of concern raised by first year students. The outcomes of the programme have included a significant reduction in the attrition rates of first year psychology students (from $21.6 \%$ to $6.8 \%$ in just four years), increased student satisfaction with studying psychology at ECU and improved ranking of the School of Psychology to sixth out of 32 Australian psychology schools or departments in 2005. This paper begins by outlining previous literature on transition to university, followed by a description of the programme and a detailed discussion of the outcomes as they relate to the School of Psychology.

\section{The transition to university}

The transition from high school to university can be particularly challenging. Examples of the stressors that first year university students commonly encounter include: the need to develop new relationships with peers and faculty; adjusting to the task of being an independent active learner; learning successful time management skills; and experiencing a change in their relationship with parents and family (Parker, Summerfeldt, Hogan and Majeski, 2004). Research indicates that a significant proportion of first year university students are more likely to withdraw from their respective course than students in later years (Jones, 1998). There is also evidence indicating that withdrawing early may cause emotional distress to the individual (Connor and McKavanagh,
1997). In addition, there is the economic cost both to the student and the university (Gerdes and Mallinckrodt, 1994; Shelton, 2003) which results in much attention being directed at developing strategies that aid students' transition to university (e.g. Lamothe et al., 1995; Peat, Dalziel and Grant, 2001; Pratt, 2000).

The undergraduate psychology programme at ECU includes high school leavers $(80 \%)$ and mature-age $(20 \%)$ students. Students in the first year undergraduate programme undertake four units in each of two semesters. Each unit of study involves a minimum of three contact hours per week for a 13-week semester. Over the past 10 years, we have averaged around 300 students enrolled in our introduction to psychology unit.

In an attempt to understand the difficulties encountered by first year psychology students and the underlying causes of attrition, the School of Psychology in 2002 conducted individual interviews and focus groups that explored student experiences in their first year of university. This investigation revealed a number of commonalities amongst our first year psychology students. For example, many commencing students were first generation university students and research has suggested that a large proportion of these students lack realistic expectations in relation to the demands involved in studying at a tertiary level (Chang, Cohen, Pike, Pooley and Breen, 2003). First year psychology students were also found to have a number of misconceptions about the discipline of psychology; for example, that psychology is only concerned with counselling and psychoanalysis. Evidently, students are surprised to

${ }^{1}$ Corresponding author: Lynne Cohen, School of Psychology, Edith Cowan University, 100 Joondalup Drive, Joondalup, Western Australia, Australia 6027. Email may be sent to I.cohen@ecu.edu.au 
learn that psychology is in fact a challenging discipline that involves mathematics, science and research. In addition to this, many first year psychology students were found to lack sufficient knowledge and skills in science and mathematics, and subsequently experienced a great deal of anxiety about the prospect of studying such subjects at a tertiary level. In conclusion, our surveys found that first year psychology students commonly reported negative feelings such as stress, confusion, disillusionment and exhaustion when commencing their psychology studies at university (Darlaston-Jones et al., 2003).

\section{The role of social support}

The problems listed above are consistently cited in the literature as being linked to high levels of attrition (e.g. Chang, Cohen, Pike, Pooley and Breen, 2003; Faiers, 1998; Jones, 1998). One effective way to aid the transition to university is through the provision of social support (Jay and D'Augelli, 1991). Social support is defined as perceived instrumental, emotional, informational and appraisal support provided to an individual by family, friends and the wider community (Day and Livingstone, 2003). Social support is said to be beneficial for first year university students as it encourages successful adaptation to the university environment (Hinderlie and Kenny, 2002; Lamothe, 1995; Pratt, 2000). In addition, students who experience social support are reported to be more inclined to adopt positive coping techniques (Tao, Dong, Pratt, Hunsberger and Pancer, 2000), have a more positive view of the university environment, have increased self-esteem (Gloria and Ho, 2003), experience psychological and physical well-being (Jay and D'Augelli, 1991) and are more inclined to attend class (Pratt et al., 2000). Thus, the idea of providing adequate social support for our students formed the framework for developing the seven components of our holistic strategy aimed at supporting first year students.

It is vital that adequate support at the tertiary or higher education (HE) level is provided for commencing students, to aid their transition into university. In 2002, we researched many transition programmes that have been implemented at different universities and determined that a single approach was not likely to cover the range of different needs that incoming students required. Rather, our philosophy of transition into HE studies is derived and adapted from over 30 years of research on psychological sense of community (e.g. Glynn, 1981; McMillan and Chavis, 1986; Sarason, 1974; Wandersman, 1981). A defining aspect of this approach is that it encourages the creation of an environment in which there is a strong sense of belonging and commitment to enhancing the quality of teaching and learning. With this in mind, the School of Psychology at ECU adopted a holistic approach to transition, through action research, by consistently evaluating and refining our programme. Each of the individual components of our strategy is likely to result in some success, but we believed that, taken as a whole, the seven components together were likely to form a holistic strategy that enhanced students' sense of belonging to the School of Psychology.

This paper describes our programme, known as EQUAL (Enhancing Quality and Learning) and outlines each of the seven EQUAL components: peer mentoring, formation of learning communities, curriculum reforms, tutor training, orientation, the development of student portfolios and school liaison. In addition, we describe the evaluations of the programme that have been carried out that led us to believe that enhancing sense of belonging in students is an effective strategy for successful transition into university. The specific contribution of each of these seven components is described below.

\section{Peer mentoring}

Peer mentoring involves the recruitment of senior students to mentor incoming students. The goal of a mentoring relationship is to create an environment in which all students can obtain the help they require from more experienced students or staff in the School of Psychology. The benefits of mentoring include enhancing emotional support through having the opportunity to share one's joys, disappointments and concerns (Pelliccione and Albon, 2004); providing comprehensive campus orientation; extending one's friendship networks (Breen et al., 2001); gaining insight into and knowledge about one's chosen course; and learning useful study techniques (Fowler, 2004). Mentees generally report an increase in self-efficacy, which may be explained by having contact with an individual who has successfully integrated into the university academic and social environment and who has persisted with their studies (Gloria, Robinson-Kurpius, Hamilton and Wilson, 1999).

Mentors also experience a number of benefits when participating in mentoring. For example, mentors report personal benefits such as feeling a sense of reward gained by assisting and supporting new students (Fowler, 2004) as well as an increased feeling of selfworth (Breen et al., 2001). Mentors also experience professional benefits such as the opportunity to develop communication, interpersonal and empathy skills (Breen et al., 2001). Furthermore, mentors generally enjoyed the opportunity to share their own experiences and knowledge in relation to university (Chang et al., 2003). Taking into consideration the multiple advantages associated with peer mentoring it is evident as to why it is becoming an increasingly popular strategy to enhance retention of first year university students.

We believed that our second and third year students represented an untapped but valuable resource that could demystify the university as an institution and encourage first year students to ask questions and solve problems in a friendly, nonthreatening environment. About $45 \%$ 
of our second and third year students volunteered to participate in the programme, which was initially trialled in 1998, with full implementation in 1999. We adopted an approach in which each commencing first year student was assigned a second or third year mentor. We selected mentors on the basis of their stated interests, hobbies and demographics, and matched mentees with similar characteristics. Each mentoring group had about five first year students and all of the mentors were formally trained in a day-long workshop in which we addressed issues such as coping skills, communication skills and self-care.

Our peer mentoring programme was continually evaluated at the end of each semester using standardised semi-structured open-ended questionnaires and the information generated from the evaluation was used to improve the design of the programme. Taking into account the attrition rate of $21.6 \%$ for first year psychology students in 1999, the Peer Mentoring Programme helped to reduce attrition to $13.3 \%$ in 2000 and to $6.8 \%$ in 2004 . Based on the continuing success and popularity of our programme, peer mentoring has been extended to include online mentoring for external (off-campus distance education) students.

\section{Formation of learning communities}

Extending the notion of social support is the development of learning communities. Learning communities involve dividing a cohort of students (generally first year) into smaller units or groups of students (Knight, 2003). Students then attend classes with their respective cohort for a designated length of time, generally until completion of the first year. The aim of a learning community is to provide an optimal environment that allows first year students to become fully integrated, socially and academically, into the university environment and to engender a sense of belonging to their course.

Two main characteristics of learning communities relate to facilitation and active learning. In a learning community, the teaching staff relinquish their role as an 'expert' and become facilitators for the students in the learning community (DeMulder and Eby, 1999). Conversely, the students progress from being passive learners to active learners (Twigg, 2003). That is, the development of learning communities enhances student-centred learning where collaboration, active learning and student engagement become the focus of teaching and learning.

The literature suggests that learning communities are an effective mechanism for enhancing students' adjustment and commitment to university (e.g. Knight, 2003). However, the benefits of learning communities extend beyond the university environment. Students involved in learning communities develop valuable skills that will prove to be most useful in professional employment. Examples of skills developed in learning communities include collaborative teamwork, experience in working with diverse perspectives and opinions, and conflict resolution (DeMulder and Eby, 1999).

We found that many of our first year students felt extremely isolated during their first few weeks at university. A failure to connect to the social environment within the university had a detrimental effect on their decision to persist with their HE studies. In an attempt to enhance students' sense of belonging to the university's social and academic environment, staff within the School of Psychology organised the learning communities in the formation of study groups within a supportive friendship network. This initiative had the support of all staff teaching into the first year programme. This approach was originally championed by Tinto and his colleagues (Tinto, 1993; Tinto and Love, 1995) and through these communities, students experience a higher level of connection with staff and fellow students. This, in turn, creates an environment conducive to collegiality and is less isolating for first year students. In other words, these formal groups provided an informal support network for first year students.

Working with the notion of community connectedness, strategies were developed to help the School of Psychology create an environment reflective of a learning community. The specific strategies included the formation of tutorial groups that stayed together for the entire first year. Communication was improved between students and the School of Psychology with a School newsletter issued every semester, a School website, upto-date notice boards and online discussions. The online site for undergraduate students is monitored daily by a staff member and the numbers of students accessing the site is recorded. Current indications are that over $80 \%$ of first year students regularly visit the School's community website. Staff also adopted an open door policy whereby students could drop in on staff and feel comfortable in doing so. Furthermore, the physical environment within the School of Psychology was improved by introducing plants, soft furniture, displays of students' work and landscaped gardens. The combination of these elements ensured that students felt a great degree of attachment to their learning environment and provided the foundation for supportive friendships to develop between students and staff as well as between the students themselves.

There are many benefits associated with introducing learning communities into the university environment. First, students develop a deep and thorough understanding of their course content through meaningful interactions in a friendly environment between the students themselves (Knight, 2003). This leads to greater student involvement in the learning process and also encourages them to engage in critical dialogue with faculty and peers (DeMulder and Eby, 1999). Second, learning communities enable students to 
develop supportive friendships with peers and it is these relationships that assist them to make the transition to university (Tinto, 1997). Third, the formation of learning communities creates a strong sense of belonging to the School of Psychology at ECU. Finally, learning communities significantly contribute to lower attrition rates (Chang et al., 2003; Dodge and Kendall, 2004; Knight, 2003; Tinto, 1997).

\section{Curriculum reform}

Scaffolding learning has been shown to improve the way in which students successfully engage with the material in the curriculum (Rogoff, Matusov and White, 1996). The necessity for curriculum reform was identified by the School of Psychology in order to minimise the academic difficulties commonly encountered by commencing students. For example, many first year students were not mathematically competent and experienced stress when faced with learning statistics. After a thorough examination of the existing curriculum, the following reforms were introduced: a restructuring of the research methods and statistics units to reflect scaffolded learning, in which statistics topics were thoroughly revised from one year to the next; updating unit content to include contemporary and interesting examples and issues; the integration of a formal set of generic skills or graduate attributes into the units; and redesigning assessment tasks to reflect generic skills or graduate attributes.

In detail, in redesigning the structure of our research methods and statistics units, we spread the content more evenly throughout the programme. This involved rearticulating the content of the three year sequence and making sure that qualitative research methods were taught from first year onwards (previously, qualitative methods were taught only in third year). This produced an integrated approach to teaching statistics, which, on reflection, better consolidated knowledge from one year to the next. Currently, about $40 \%$ of the content of the three year sequence focuses on qualitative research. We believed that this provided our School with a competitive advantage over other psychology schools in Western Australia because our students became skilled in both quantitative and qualitative research methods. This is something that our students could trumpet in their portfolios and statements of graduate attributes. In addition, the School adopted a student-centred learning approach and also incorporated technology into the first year programme. Lastly, student workbooks were introduced for use in the tutorials.

\section{Tutor training}

In addition to the curriculum reforms, another strategy employed by the School of Psychology to minimise academic difficulties in first year students is a comprehensive tutor training programme. Staff recognised that a well-designed curriculum required a consistently high standard of teaching in order to be effective. Hence, we introduced formal training for our tutors via an intensive, day-long training workshop conducted prior to the commencement of the semester. This training was designed to strengthen the quality of teaching in the first year programme and as a matter of School of Psychology, and now ECU, policy, is a mandatory requirement. We believe that the training workshop provides tutors with necessary knowledge, skills and resources to conduct tutorials with undergraduate students. The authors have developed manuals specifically designed for the workshop facilitators, the tutors and unit coordinators (Cohen, Pooley and Chang, 2006). Furthermore, mentoring has also been incorporated into the training of tutors, whereby new tutors are paired with more experienced tutors.

This emphasis on quality teaching is of particular importance as tutors are the major point of contact for first year students and consequently have the potential to impact significantly on the students' learning experience. By ensuring a high quality of teaching in the first year of university, one can anticipate greater course satisfaction from the students and we believe that this can only have a positive impact on student retention levels.

\section{Orientation}

Another initiative that has been shown to aid adjustment to university and encourage academic persistence in first year students is the provision of a comprehensive orientation programme. These programmes facilitate the transition to university as they help to alleviate stress and uncertainty by providing information, campus familiarity and the opportunity to socialise with faculty and other commencing students (Robinson, Burns and Gaw, 1996).

Orientation programmes can range from one-day events to a period of one week or more. The academic focus of the School of Psychology's orientation programme is concerned with aiding each student to adjust to a greater level of independent study and provides information relevant to academic matters, such as how to conduct a library search, accessing academic databases and so on. In addition, orientation provides information on the respective courses of study, grading policies, the institution's academic expectations of students and the policies and procedures of the university (Robinson et al., 1996).

Past research indicates that students require academic assistance in transitioning to university (Ryan and Glenn, 2004) and that tertiary institutions should consider incorporating strategies that enhance student learning skills in the orientation programme (Daddona and Cooper, 2002). Other academic skills that can be taught in the orientation programme include time management, effective note taking during lectures, reading techniques and exam preparation (Ryan and Glenn, 2004). It is important to note, however, that a well-designed and 
effective orientation programme is one that meets the unique needs of the incoming students.

Regarding the social component of our orientation programme, the primary aim is to encourage the commencing student to integrate into the social fabric of the campus. Having expectations about university that are realistic and positive has also been shown to enhance the adjustment of first year students to university (Jackson, Pancer, Pratt and Hunsberger, 2000). Therefore, commencing students are provided with the opportunity to become acquainted with the lecturing staff, peer mentors, senior students, postgraduate students, student support services and other first year students. In addition, students are given information on the available student support services and ECU's values and codes of conduct (Ryan and Glenn, 2004).

At the School of Psychology, a structured orientation programme has been developed to introduce incoming students to the physical, social and academic infrastructure of the School. This orientation programme is a full day event that occurs two weeks prior to the commencement of Semester 1. In addition to being introduced to all facets of the university environment, the orientation programme also provides commencing students with the opportunity to work with staff to develop an individual study plan. Each commencing student is given a booklet that informs them of different career pathways in psychology (Pooley and Cohen, 2007) and recommends appropriate units that will direct the student towards their future career. This process of engaging students in developing a study plan in the earliest stage of their tertiary studies ensures they have a clear strategy for achieving their future career aspirations.

\section{Development of student portfolios}

Students who complete a three year major in psychology have developed skills and competencies suitable for employment in many areas. The School of Psychology has now embedded portfolio building into the undergraduate programme. Portfolios are an excellent means of providing tangible evidence of student learning (Cooper, Cohen and Pooley, 2006). Students begin building their portfolios in the first year of study and continue to accumulate evidence of their learning throughout their degree. For example, students assemble evidence to demonstrate achievement of learning outcomes, attainment of performance indicators, proficiency in practical skills, specified areas of expertise (i.e. generic skills or graduate attributes as specified by ECU and the Australian Psychological Society), satisfactory completion of specified tasks and capacity for ongoing learning in professional life. The primary advantage of the portfolio approach is that students have the ability to demonstrate tangible examples of competencies and achievements. Indeed, these portfolios give a competitive edge to our graduates in their job pursuits (Cooper et al., 2006).

\section{School liaison}

The School of Psychology has developed a close liaison with local high school communities. The rationale for developing closer ties with high schools is to improve student transition to university and enhance students' understanding of psychology as a career prior to the commencement of their HE studies. This strategy involves communicating with principals, teachers, managers of student services, youth education officers and career counsellors to create channels through which career information can be disseminated to the high schools. It is believed that by working in partnership with local high schools, potential psychology students will enter university with more realistic expectations about psychology as a career and will experience a more positive transition to university.

\section{Programme outcomes}

As the central focus of the EQUAL programme is on first year students, one of the clearest measures of its success was the dramatic decline since its inception in student attrition rates. For example, between 20022004, the mean attrition rate for first year psychology students was $6.8 \%$, which compares favourably to the preprogramme attrition rate of $21.6 \%$. In addition to a reduction in the attrition rates, the establishment and success of the EQUAL programme has resulted in a concomitant increase in overall completion rates: the percentage of students graduating from psychology has increased from $39.2 \%$ (1998) to $70 \%$ (2004). This indicates a greater proportion of first year psychology students are persisting with their academic studies.

Additional evidence of the effectiveness of the EQUAL programme is indicated by student satisfaction with the course and student achievement, as measured by the Australian Universities Course Evaluation Questionnaire, which showed that the School of Psychology rose from a rank of 27 (out of 32 Australian universities that teach psychology) to a rank of 6 in 2005 (Good Universities Guide, 2005).

The EQUAL programme has also witnessed an increase in the number of students who participated in activities within the School of Psychology. For example, the percentage of second year students involved in conducting orientation activities has significantly increased from $0 \%$ in 1998 to $50 \%$ in 2003. In addition, the number of second and third year students who act as mentors has also increased from $10 \%$ in 1998 to $65 \%$ in 2005. Furthermore, only $15 \%$ of first year psychology students were involved in study groups in 1998, whereas in $2005,99 \%$ of first year psychology students participated in study groups.

In addition to the statistical data presented as evidence of the effectiveness of the EQUAL approach, there is evidence of students' improved learning experiences 
taken from regular monitoring by the institutional unit evaluation index. For example, since 1998, all psychology lecturers have achieved teaching scores in the top quartile, which is particularly significant given the large first year class sizes in psychology. Qualitative comments from students on ECU's unit evaluation index describe great enthusiasm from staff, high levels of empathy and great learning support, as reflected in the following comment:

I don't know if I would have kept going in psychology if she hadn't been there for me... she's a fantastic support. The Peer Mentoring Programme alleviated my overwhelming apprehension about attending university... allowing me to feel more confident, which led to more concentration on homework.

As described above, in the six years since the EQUAL programme was implemented, the School of Psychology has made some remarkable achievements. The evolution of the programme stems from a consistent process of evaluation which allows the School of Psychology to respond immediately to the needs of the students and to address criticisms of the programme. Following on from these successes, the School of Psychology has committed to expand EQUAL to enhance the quality of teaching and learning for all psychology students. In future, staff in the School of Psychology intend to expand the EQUAL programme so it is inclusive of all students involved in the three year undergraduate degree. It is planned that postgraduate students will mentor second and third year psychology students. To achieve these goals for the future, the School of Psychology will direct all available resources to support the development of these initiatives to ensure a greater majority of students will experience the benefits of the EQUAL programme.

\section{REFERENCES}

Breen, L., Cohen, L., Drew, N., Haunold, S., Pike, L. T., Pooley, J. A., et al.. (2001). Expanding horizons of peer mentoring: how can we mentor students on and off campus? In M. Kulski and A. Herrmann (Editors), New horizons in university teaching and learning: responding to change (pp.1-11). Perth, Australia: Centre for Educational Advancement, Curtin University of Technology.

Chang, P. P. W., Cohen, L., Pike, L. T., Pooley, J. A. and Breen, L. (2003). The Edith Cowan University School of Psychology Mentoring Programme: from reducing attrition to building learning communities. In F. Kochan and J. Pascarelli (Editors), Global perspectives of the reconstruction of contexts, learning communities and cultures through mentoring (pp. 277-293). Greenwich, CT: Information Age Publishing.

Cohen, L., Pooley, J. A. and Chang, P. P. W. (2006). Tutor training manual. Perth, Australia: Edith Cowan University.
Connor, J. and McKavanagh, M. (1997). Distance mentoring for tertiary students: an action learning approach. Unpublished manuscript, Central Queensland University, Queensland.

Cooper, T., Cohen, L. and Pooley, J. A. (2006). Portfolios for psychology students. Perth, Australia: Praxis Education.

Daddona, M. F. and Cooper, D. L. (2002). Comparison of freshmen perceived needs prior to and after participation in an orientation program. National Association of Student Personnel Administrators Journal, 39(4), 300-318.

Darlaston-Jones, D., Pike, L. T., Cohen, L., Drew, N. M., Young, A. H. C. and Haunold, S. (2001, August). Are they being served? Student expectations of higher education. Paper presented at the 15th Annual Western Australian Institute for Educational Research Forum, Perth, Australia.

Day, A. L. and Livingstone, H. A. (2003). Gender differences in perceptions of stressors and utilization of social support among university students. Canadian Journal of Behavioural Science, 35, 73-83.

DeMulder, E. K. and Eby, K. K. (1999). Bridging troubled waters. Learning communities for the 21 st century. American Behavioral Scientist, 42, 892-901.

Dodge, L. and Kendall, M. E. (2004). Learning communities. College Teaching, 52, 150-155.

Fowler, J. (2004). The tiered mentoring program: linking students with peer and professionals. Higher Education Research and Development Society of Australia News, 26, 18-19.

Gerdes, H. and Mallinckrodt, B. (1994). Emotional, social and academic adjustment of college students: a longitudinal study of retention. Journal of Counseling and Development, 72, 281-288.

Gloria, A. M. and Ho, T. A. (2003). Environmental, social and psychological experiences of Asian American undergraduates: examining issues of academic persistence. Journal of Counseling and Development, 81, 93-105.

Gloria, A. M., Robinson-Kurpius, S. E., Hamilton, K. D. and Willson, M. S. (1999). African American students' persistence at a predominantly white university: influences of social support, comfort and self beliefs. Journal of College Student Development, 40, 257-268.

Glynn, T. J. (1981). Psychological sense of community: measurement and application. Human Relations, 34, 780818.

Good universities guide. (2005). Melbourne, Australia: Hobsons.

Hinderlie, H. H. and Kenny, M. (2002). Attachment, social support and college adjustment among Black students at predominantly White universities. Journal of College Student Development, 43, 327-340.

Jackson, L. M., Pancer, S. M., Pratt, M. W. and Hunsberger, B. E. (2000). Great expectations: the relation between expectancies and adjustment during the transition to university. Journal of Applied Social Psychology, 30, 21002125.

Jay, G. M. and D'Augelli, A. R. (1991). Social support and adjustment to university life: a comparison of African American and White freshmen. Journal of Community Psychology, 19, 95-108. 
Jones, B. (1998, July). The transition from secondary school to university: who needs help coping and when? Paper presented at the Pacific Rim Conference - First Year in Higher Education, Auckland, New Zealand.

Knight, W. E. (2003). Learning communities and first year programs: lessons for planners. Planning for Higher Education, 31, 5-12.

Lamothe, D., Currie, F., Alisat, S., Sullivan, T., Pratt, M., Pancer, S. M., et al. (1995). Impact of a social support intervention on the transition to university. Canadian Journal of Community Mental Health, 14, 167-180.

McMillan, D. W. and Chavis, D. M. (1986). Sense of community: a definition and theory. Journal of Community Psychology, 14, 6-23.

Parker, J. D. A., Summerfeldt, L. J., Hogan, M. J. and Majeski, S. A. (2004). Emotional intelligence and academic success: examining the transition from high school to university. Personality and Individual Differences, 36, 163-172.

Peat, M., Dalziel, J. and Grant, A. M. (2001). Enhancing the first year student experience by facilitating the development of peer networks through a one-day workshop. Higher Education Research and Development, 20, 199-215.

Pelliccione, L. and Albon, R. (December, 2004). Beyond the comfort zone: using informal mentoring to create lifelines for student disequilibrium. Paper presented at the 21st Annual Conference for the Australasian Society for Computers in Learning in Tertiary Education (ASCILITE), Perth. Figtree, Australia::ASCILITE. Retrieved April 4, 2008, from http:// www.ascilite.org.au/conferences/perth04/procs/pdf/ pelliccione.pdf

Pooley, J. A. and Cohen, L. (2007). Why study psychology? Melbourne, Australia: Social Science Press.

Pratt, M. W., Bowers, C., Terzian, B., Hunsberger, B., Mackey, K., Thomas, N., et al. (2000). Facilitating the transition to university: evaluation of a social support discussion intervention program. Journal of College Student Development, 41, 427-441.

Robinson, D. A. G., Burns, C. F. and Gaw, K. F. (1996). Orientation programs: a foundation for student learning and success. New Directions for Student Services, 75, 55-68.
Rogoff, B., Matusov, B. and White, S. (1996). Models of teaching and learning: participation in a community of learners. In D. Olson and N. Torrance (Editors), The handbook of cognition and human development (pp. 388414). Oxford, UK: Blackwell.

Ryan, M. P. and Glenn, P. A. (2004). What do first year students need most: learning strategies instruction or academic socialization? Journal of College Reading and Learning, 34, 4-28.

Sarason, S. B. (1974). The psychological sense of community: perspectives for community psychology. San Francisco, CA: Jossey-Bass.

Shelton, E. N. (2003). Faculty support and student retention. Journal of Nursing Education, 42, 68-76.

Tao, S., Dong, Q., Pratt, M. W., Hunsberger, B. and Pancer, S. M. (2000). Social support: relations to coping and adjustment during the transition to university in the People's Republic of China. Journal of Adolescent Research, 15, 123-144.

Tinto, V. (1993). Building community. Liberal Education, 79, 16-21.

Tinto, V. (1997). Classrooms as communities: exploring the educational character of student persistence. Journal of Higher Education, 68, 599-623.

Tinto, V. and Love, A. G. (1995). A longitudinal study of learning communities at LaGuardia Community College. University Park, PA: National Centre on Postsecondary Teaching, Learning and Assessment, Pennsylvania State University. Retrieved April 8, 2008 from http:// www.eric.ed.gov/ERICDocs/data/ericdocs2sql/content_ storage_01/0000019b/80/29/af/e6.pdf

Twigg, C. A. (2003). Improving quality and reducing cost: designs for effective learning. Change, 35, 23-29.

Wandersman, A. (1981). A framework of participation in community organisations. Journal of Applied Behavioral Science, 17, 27-58.

Manuscript received on 31 August 2006.

Revision accepted for publication on 2 October 2007. 